\title{
Common Psychological Factors in Chronic Diseases
}

\author{
Ciro Conversano* \\ Department of Surgical, Medical, Molecular and Critical Pathology, University of Pisa, Pisa, Italy
}

Keywords: psychological factors, quality of life, emotional distress, chronic diseases, adherence

The construct of "chronic physical diseases" (CPDs) encompasses a number of heterogeneous conditions that have persisting lifelong effects on the quality of life (QoL) and subjective well-being (Sprangers et al., 2000). According to epidemiological studies, CPDs are constantly increasing, not only in Western countries but also in developing/emerging countries, with certain prevalent differences regarding CPD type (Vos et al., 2016), raising questions on the multifactorial genesis of this phenomenon. The role of psychiatric disorders is, for example, well-known as comorbid conditions able to affect the course of CPD with a number of sequelae and complications (Daré et al., 2019).

The most common CPDs (namely, cardiovascular disease, diabetes mellitus, neoplastic diseases, asthma, arthritis, and osteoporosis) are often complicated by psychiatric symptoms or emotional/psychological subjective suffering (Martino G. et al., 2019; Rosa et al., 2019), a datum that underlines the close correlation that exists between such conditions. However, the relationships and the mutual influences between CPD and psychopathological manifestations are far from established (Marchini et al., 2018; Miniati et al., 2018; Martino G. et al., 2019).

Findings on psychological/psychopathological dimensions in patients with CPD, both from a cross-sectional and from a lifetime perspective, are available in the literature, with an emphasis on their impact on cognitive functioning, emotional processing, exposition to stressful events (SLEs) and adversities, medical and psychological outcomes, and combined interventions and therapies (Bernard et al., 2018; McGilton et al., 2018; Shao et al., 2019). A number of studies have, for instance, already explored the impact of signs and symptoms belonging to the realm of psychopathological disorders on the most common CPDs, with a measure of the subjective perception of wellbeing and QoL (Megari, 2013). More specifically, alexithymia, anxiety, depression, psychological distress, sleep quality, and emotional dysregulations have been systematically assessed in patients with fibromyalgia, Type 2 diabetes, psoriasis, and osteoporosis (Palagini et al., 2016; Catalano et al., 2018; Martino et al., 2018a,b; Cristina et al., 2019; Kelly et al., 2019; Marchi et al., 2019; Martino M. L. et al., 2019; Settineri et al., 2019a,b). This datum represents the increasing tendency of the scientific community to take an interest in the aforementioned connection between the psychological and physical spheres, hypothesizing a positive correlation between the two, where a higher psychological and QoL malaise correspond to the increasing severity of the pathology.

In nearly all of the abovementioned conditions, cognitive functioning and performances were impaired, as enhanced by studies with cognitive tasks, again raising questions as to the different weight and role of metabolic dysregulations vs. comorbid anxiety or depressive disorders in determining the severity of cognitive dysfunctions (Guicciardi et al., 2019).For example, emotional processing and depression has been found to enhance "pain catastrophization," which could be described as the cognitive attitude of interpreting the experience of pain in an excessively negative manner, during upper endoscopy in young, especially female, patients, when exposed for the first time to diagnostic procedures and pain therapies (Sullivan et al., 2001; Lauriola et al., 2019). A number of studies also highlight the reciprocal influences between psychological and medical conditions in affecting cognitive performances and emotional reactions among children and young adults, with relevant sequelae in adulthood and in the elderly, while other studies have 
opened up debate on the interaction of age, gender, and medical conditions on mental status (see the association between early childhood SLEs, depression, cognitive functioning, and lipids' metabolism alterations; Stewart et al., 2000; Péterfalvi et al., 2019). Other studies demonstrate how an early diagnosis of a neuropsychiatric condition (such as ADHD) may change the electrophysiological characteristics and the overall subjective neuropsychological profile during adulthood (Angela et al., 2018; Klein et al., 2019), as possibly determined by the occurrence of manic symptoms and PTSD in young adults (Dell'Osso et al., 2014) or the emotional suppression or oneiric perturbation in subjects affected by psychosomatic illnesses (Settineri et al., 2019a,b).

Overall, these studies demonstrate the importance of a multidisciplinary approach in treating patients affected by CPD and both psychological and psychopathological disorders. Both psychological and physical interventions in patients with CPD could ameliorate prognosis, considering the described relationships between psychological factors and CPD, as identified by studies on the positive impact of a healthy psychological functioning on CPD (Schiavon et al., 2017; Gentili et al., 2019). Psycho-educational interventions, mindfulnessbased cognitive therapy, non-invasive brain stimulation techniques, peer-to-peer supports, and a health-based approach have been all tested with promising results in patients with CPD (Castelnuovo et al., 2015; De Jong et al., 2016; Naro et al., 2016; Callus and Pravettoni, 2018; Conversano et al., 2019).

\section{REFERENCES}

Angela, F. R., Capri, T., Mohammadhasani, N., Gangemi, A., Gagliano, A., and Martino, G. (2018). Frequency bands in seeing and remembering: comparing ADHD and typically developing children. Neuropsychol. Trends 24, 99. doi: 10.7358/neur-2018-024-fabi

Bernard, P., Romain, A. J., Caudroit, J., Chevance, G., Carayol, M., Gourlan, M., et al. (2018). Cognitive behavior therapy combined with exercise for adults with chronic diseases: Systematic review and meta-analysis. Health Psychol. 37:433. doi: $10.1037 /$ hea0000578

Callus, E., and Pravettoni, G. (2018). The role of clinical psychology and peer to peer support in the management of chronic medical conditions-a practical example with adults with congenital heart disease. Front. Psychol. 9:731. doi: 10.3389/fpsyg.2018.00731

Castelnuovo, G., Zoppis, I., Santoro, E., Ceccarini, M., Pietrabissa, G., Manzoni, G. M., et al. (2015). Managing chronic pathologies with a stepped mHealthbased approach in clinical psychology and medicine. Front. Psychol. 6:407. doi: 10.3389/fpsyg.2015.00407

Catalano, A., Martino, G., Bellone, F., Gaudio, A., Lasco, C., Langher, V., et al. (2018). Anxiety levels predict fracture risk in postmenopausal women assessed for osteoporosis. Menopause 25, 1110-1115. doi: 10.1097/GME.0000000000001123

Conversano, C., Poli, A., Ciacchini, R., Hitchcott, P., Bazzichi, L., and Gemignani, A. (2019). A psychoeducational intervention is a treatment for fibromyalgia syndrome. Clin. Exp. Rheumatol. 37, S98-S104.

Cristina, C. N., Mario, F., and Paolo, A. (2019). Expressive suppression and negative affect, pathways of emotional dysregulation in psoriasis patients. Front. Psychol. 10:1907. doi: 10.3389/fpsyg.2019.01907

Daré, L. O., Bruand, P. E., Gérard, D., Marin, B., Lameyre, V., Boumédiène, F., et al. (2019). Co-morbidities of mental disorders and chronic physical diseases in developing and emerging countries: a meta-analysis. BMC Public Health 19:304. doi: 10.1186/s12889-019-6623-6
In conclusion, it could be inferred that the bidirectional association between CPD and psychopathological factors might lead to an exacerbation of both conditions, with mechanisms that are only partially known and described. However, a relevant corpus of knowledge supports the need for an integrated approach (physical, psychological, and psychopathological) that takes into account the subjective experience of the single patient from a lifetime perspective. As a consequence, it is necessary to consider the corollary of symptoms that the patient who suffers from a chronic disorder manifests as a unitary corpus, where it is possible to intervene both with medical and psychological science to improve QoL and therefore physical symptoms. In the history of the patient's illness, the weight of psychological variables plays a fundamental and non-negligible role when the doctor's interest is that of treating the patient from a long-term perspective.

The development of therapeutic interventions able to fuse different perspectives into a tailor-made interdisciplinary management approach in a single patient and the development of a quality body of research on the topic are future challenges in order to improve QoL and the subjective well-being of patients with CPD and psychopathological signs and symptoms.

\section{AUTHOR CONTRIBUTIONS}

CC was responsible for writing the entire opinion article, for checking the adequacy of references and of all aspects of layout.

De Jong, M., Lazar, S. W., Hug, K., Mehling, W. E., Hölzel, B. K., Sack, A. T., et al. (2016). Effects of mindfulness-based cognitive therapy on body awareness in patients with chronic pain and comorbid depression. Front. Psychol. 7:967. doi: 10.3389/fpsyg.2016.00967

Dell'Osso, L., Stratta, P., Conversano, C., Massimetti, E., Akiskal, K. K., Akiskal, H. S., et al. (2014). Lifetime mania is related to post-traumatic stress symptoms in high school students exposed to the 2009 L'Aquila earthquake. Compr. Psychiatry 55, 357-362. doi: 10.1016/j.comppsych.2013.08.017

Gentili, C., Rickardsson, J., Zetterqvist, V., Simons, L., Lekander, M., and Wicksell, R. K. (2019). Psychological flexibility as a resilience factor in individuals with chronic pain. Front. Psychol. 10:2016. doi: 10.3389/fpsyg.2019.02016

Guicciardi, M., Crisafulli, A., Doneddu, A., Fadda, D., and Lecis, R. (2019). Effects of metabolic syndrome on cognitive performance of adults during exercise. Front. Psychol. 10:1845. doi: 10.3389/fpsyg.2019.01845

Kelly, R. R., McDonald, L. T., Jensen, N. R., Sidles, S. J., and LaRue, A. C. (2019). Impacts of psychological stress on osteoporosis: clinical implications and treatment interactions. Front. Psychiatry 10:200. doi: 10.3389/fpsyt.2019.00200

Klein, M., Silva, M. A., Belizario, G. O., de Almeida Rocca, C. C., Serafim, A. D. P., and Louzã, M. R. (2019). Longitudinal neuropsychological assessment in two elderly adults with attention-deficit/hyperactivity disorder: case report. Front. Psychol. 10:1119. doi: 10.3389/fpsyg.2019.01119

Lauriola, M., Tomai, M., Palma, R., La Spina, G., Foglia, A., Panetta, C., et al. (2019). Intolerance of uncertainty and anxiety-related dispositions predict pain during upper endoscopy. Front. Psychol. 10:1112. doi: 10.3389/fpsyg.2019.01112

Marchi, L., Marzetti, F., Orrù, G., Lemmetti, S., Miccoli, M., Ciacchini, R., et al. (2019). Alexithymia and psychological distress in patients with fibromyalgia and rheumatic disease. Front. Psychol. 10:1735. doi: 10.3389/fpsyg.2019.01735

Marchini, F., Caputo, A., Napoli, A., Balonan, J. T., Martino, G., Nannini, V., et al. (2018). Chronic illness as loss of good self: underlying mechanisms affecting diabetes adaptation. Mediterranean J. Clin. Psychol. 6. doi: 10.6092/2282-1619/2018.6.1981 
Martino, G., Catalano, A., Bellone, F., Langher, V., Lasco, C., Penna, A., et al. (2018a). Quality of life in postmenopausal women: which role for vitamin D? Mediterranean J. Clin. Psychol. 6. doi: 10.6092/2282-1619/2018. 6.1875

Martino, G., Catalano, A., Bellone, F., Russo, G. T., Vicario, C. M., Lasco, A., et al. (2019). As time goes by: anxiety negatively affects the perceived quality of life in patients with type 2 diabetes of long duration. Front. Psychol. 10:1779. doi: 10.3389/fpsyg.2019.01779

Martino, G., Catalano, A., Bellone, F., Sardella, A., Lasco, C., Caprì, T., et al. (2018b). Vitamin D status is associated with anxiety levels in postmenopausal women evaluated for osteoporosis. Mediterranean J. Clin. Psychol. 6. doi: 10.6092/2282-1619/2018.6.1740

Martino, M. L., Gargiulo, A., Lemmo, D., Dolce, P., Barberio, D., Abate, V., et al. (2019). Longitudinal effect of emotional processing on psychological symptoms in women under 50 with breast cancer. Health Psychol. Open 6:2055102919844501. doi: 10.1177/2055102919844501

McGilton, K. S., Vellani, S., Yeung, L., Chishtie, J., Commisso, E., Ploeg, J., et al. (2018). Identifying and understanding the health and social care needs of older adults with multiple chronic conditions and their caregivers: a scoping review. BMC Geriatr. 18:231. doi: 10.1186/s12877-018-0925-x

Megari, K. (2013). Quality of life in chronic disease patients. Health Psychol. Res. 1:e27. doi: 10.4081/hpr.2013.932

Miniati, M., Fabrini, M. G., Genovesi Ebert, F., Mancino, M., Maglio, A., Massimetti, G., et al. (2018). Quality of life depression and anxiety in patients with uveal melanoma: a review. J. Oncol. 2018:5253109. doi: 10.1155/2018/5253109

Naro, A., Milardi, D., Russo, M., Terranova, C., Rizzo, V., Cacciola, A., et al. (2016). Non-invasive brain stimulation, a tool to revert maladaptive plasticity in neuropathic pain. Front. Hum. Neurosci. 10:376. doi: 10.3389/fnhum.2016.00376

Palagini, L., Carmassi, C., Conversano, C., Gesi, C., Bazzichi, L., Giacomelli, C., et al. (2016). Transdiagnostic factors across fibromyalgia and mental disorders: sleep disturbances may play a key role. A clinical review. Clin. Exp. Rheumatol. 34, 140-144.

Péterfalvi, Á., Németh, N., Herczeg, R., Tényi, T., Miseta, A., Czéh, B., et al. (2019). Examining the influence of early life stress on serum lipid profiles and cognitive functioning in depressed patients. Front. Psychol. 10:1798. doi: 10.3389/fpsyg.2019.01798

Rosa, V., Tomai, M., Lauriola, M., Martino, G., and Di Trani, M. (2019). Body mass index, personality traits, and body image in Italian preadolescents: an opportunity for overweight prevention. Psihologija doi: 10.2298/PSI181121009R. [Epub ahead of print].
Schiavon, C. C., Marchetti, E., Gurgel, L. G., Busnello, F. M., and Reppold, C. T. (2017). Optimism and hope in chronic disease: a systematic review. Front. Psychol. 7:2022. doi: 10.3389/fpsyg.2016.02022

Settineri, S., Frisone, F., Alibrandi, A., and Merlo, E. M. (2019a). Emotional suppression and oneiric expression in psychosomatic disorders: early manifestations in emerging adulthood and young patients. Front. Psychol. 10:1897. doi: 10.3389/fpsyg.2019.01897

Settineri, S., Frisone, F., Merlo, E. A., Geraci, D., and Martino, G. (2019b). Compliance, adherence, concordance, empowerment, self-management. Five words to manifest a relational misadjustment in diabetes. J. Multidiscip. Healthc. 12, 299-314. doi: 10.2147/JMDH.S193752

Shao, J., Yang, H., Zhang, Q., Du, W., and Lei, H. (2019). Commonalities and differences in psychological adjustment to chronic illnesses among older adults: a comparative study based on the stress and coping paradigm. Int. J. Behav. Med. 26, 143-153. doi: 10.1007/s12529-019-09773-8

Sprangers, M. A., de Regt, E. B., Andries, F., van Agt, H. M., Bijl, R. V., de Boer, J. B., et al. (2000). Which chronic conditions are associated with better or poorer quality of life? J. Clin. Epidemiol. 53, 895-907. doi: 10.1016/S0895-4356(00)00204-3

Stewart, S. T., Zelinski, E. M., and Wallace, R. B. (2000). Age, medical conditions, and gender as interactive predictors of cognitive performance: the effects of selective survival. J. Gerontol. Series B Psychol. Sci. Soc. Sci. 55, P381-P383. doi: 10.1093/geronb/55.6.P381

Sullivan, M. J., Thorn, B., Haythornthwaite, J. A., Keefe, F., Martin, M., Bradley, L. A., et al. (2001). Theoretical perspectives on the relation between catastrophizing and pain. Clin. J. Pain 17, 52-64. doi: 10.1097/00002508-200103000-00008

Vos, T., Allen, C., Arora, M., Barber, R. M., Bhutta, Z. A., Brown, A., et al. (2016). Global, regional, and national incidence, prevalence, and years lived with disability for 310 diseases and injuries, 1990-2015: a systematic analysis for the Global Burden of Disease Study 2015. Lancet 388, 1545-1602.

Conflict of Interest: The author declares that the research was conducted in the absence of any commercial or financial relationships that could be construed as a potential conflict of interest.

Copyright (C) 2019 Conversano. This is an open-access article distributed under the terms of the Creative Commons Attribution License (CC BY). The use, distribution or reproduction in other forums is permitted, provided the original author $(s)$ and the copyright owner(s) are credited and that the original publication in this journal is cited, in accordance with accepted academic practice. No use, distribution or reproduction is permitted which does not comply with these terms. 